\title{
O LUGAR DO ESTADO NA QUESTÃO DAS DROGAS: O PARADIGMA PROIBICIONISTA E AS ALTERNATIVAS
}

\author{
MAURÍCIO FIORE
}

[1] Sobre os desdobramentos do proibicionismo, ver, entre outros, Labate, Beatriz, Fiore, Maurício e Goulart, Sandra. "Introdução". In: Labate, B. et al. Drogas e cultura: novas perspectivas. Salvador:Edufba/Ministério da Cultura, 2008.

[2] Entre uma ampla bibliografia sobre a história do proibicionismo nos EUA e seus desdobramentos internacionais, ver Escohotado, Antonio. Historia de las Drogas, vol. 3. Madri: Alianza, 1998; Davenport-Hines, Richard. La búsqueda del olvido. Madri: Turner/ Fondo de Cultura Económica, 2001; e Rodrigues, Thiago. Politica e drogas nas Américas. São Paulo: Educ/ Fapesp, 2004.
A guerra mundial contra as drogas - nome pelo qual ficaram conhecidas parte das substâncias psicoativas que alteram a consciência ea percepção - completa, este ano, um século. Ainda que as resoluções da Primeira Conferência Internacional do Ópio de 1912, realizada em Haia, tenham sido praticamente abandonadas nos anos conturbados entre as duas grandes guerras, o modelo ali esboçado foi triunfante. Defendida, patrocinada e sediada pelos EUA, já sob a coordenação da ONU, a Convenção Única sobre Entorpecentes, de 1961, implantou globalmente o paradigma proibicionista no seu formato atual. Os países signatários da Convenção se comprometeram à luta contra o "flagelo das drogas" e, para tanto, a punir quem as produzisse, vendesse ou consumisse.

Proibicionismo é uma forma simplificada de classificar o paradigma que rege a atuação dos Estados em relação a determinado conjunto de substâncias. Seus desdobramentos, entretanto, vão muito além das convenções e legislações nacionais. O proibicionismo modulou o entendimento contemporâneo de substâncias psicoativas quando estabeleceu os limites arbitrários para usos de drogas legais/positivas eilegais/ negativas. Entre outras consequências, a própria produção científica terminou entrincheirada, na maior parte das vezes do lado "certo" da batalha, ou seja, na luta contra as drogas ${ }^{1}$. O proibicionismo não esgota o fenômeno contemporâneo das drogas, mas o marca decisivamente.

Ainda que escape da ambição deste artigo traçar a genealogia da emergência das drogas como questão contemporânea, é preciso ressaltarque não se "explica" o empreendimento proibicionista por uma única motivação histórica. Sua realização se deu numa conjunção de fatores, que incluem a radicalização política do puritanismo norte-americano, o interesse da nascente indústria médico-farmacêutica pela monopolização da produção de drogas, os novos conflitos geopolíticos do século xxe o clamor das elites assustadas com a desordem urbana.Além disso, sem desconhecer a importância histórica do pioneirismo e do empenho dos EUA para torná-la universal,é preciso notar que somente convergências locais na mesma direção puderam fazer da proibição uma realidade glo$\mathrm{bal}^{2}$. O caso brasileiro, nesse sentido, é exemplar, na medida em que as legislações proibicionistas foram criadas pari passo às norte-americanas 
e, no caso específico da maconha, droga já há muito estigmatizada pelas elites locais, a perseguição oficializou-se primeiro aqui³.

Pode-se dizer que três conjuntos de substâncias e/ ou plantas foram eleitas alvos-padrão do paradigma proibicionista: papoula/ ópio/ heroína, coca/ cocaína e cannabis/ maconha. Ainda que o conceito farmacológico de droga seja muito mais amplo — "substância que, quando administrada ou consumida por um ser vivo, modifica uma ou mais de suas funções, com exceção daquelas substâncias necessárias para a manutenção da saúde normal" - é a esse conjunto de substâncias que o termo passou a ser aplicado4. Entre as drogas, há as psicoativas ou psicotrópicas, que têm como característica principal a ação sobre o funcionamento do cérebro. Hoje, o termo "drogas" pode se referir tanto a seu sentido farmacológico, muito mais amplo, quanto a um conjunto bem mais restrito, ainda que flexível, de substâncias psicoativas, notadamente as ilícitas.

Do ponto de vista conceitual, a Convenção Internacional de 1961 definiu um modelo que permanece vigentee divide as drogas e suas plantas originárias em listas. O critério, por sua vez, seria o potencial de abuso e suas aplicações médicas. A primeira lista é composta daquelas com alto potencial de abuso e nenhum uso medicinal e, como esperado, ali estão incluídas, entre outras, as três drogas-alvo do proibicionismo: heroína, cocaína e maconha.As outras listas reúnem drogas com potencial de abuso, mas conhecido uso medicinal (morfina e anfetaminas, por exemplo) e precursores (substâncias e outros materiais empregados na produção de drogas proibidas) 5 . Diferente de muitas outras convenções, essas foram seguidas com incrível rigidez pela maior parte dos signatários.

Independente de seus intricados feixes e nuances, sustento que o paradigma proibicionista é composto de duas premissas fundamentais:1) o uso dessas drogas é prescindível e intrinsecamente danoso, portanto não pode ser permitido; 2) a melhor forma de o Estado fazer isso é perseguir e punir seus produtores, vendedores e consumidores. Assim, interessa apresentá-las, seguindo sua própria lógica, mais detalhadamente.

Primeira premissa proibicionista: o consumo de drogas é uma prática prescindivel e danosa, o que justifica sua proibição pelo Estado

A ingestão de qualquer uma das drogas proscritas é fisiológica e mentalmente danosa. Os danos fisiológicos podem ocorrer em curto ou médio prazo. Caso seja continuado, o consumo dessas drogas encadeia graves consequências, podendo levar, inclusive, à morte, seja por deterioração da saúde geral, seja por intoxicação acidental (overdose). Não há padrão, quantidade ou nível seguro para o consumo dessas drogas.

Essas drogas provocam dependência. Por ser inicialmente prazeroso, seu consumo tem grande chance de levar seus consumidores à
[3] No Brasil, a maconha foi considerada definitivamente ilegal em 1932, cinco anos antes de o mesmo ocorrer nos EUA.

\begin{abstract}
[4] A polissemia e a ambiguidade do termo "drogas" são algumas das principais características do debate sobre o tema. Em trabalho anterior, grafei o termo sempre entre aspas para justamente indicar "perigo". Para mais detalhes sobre a importância do conceito de drogas, ver Fiore, Maurício. Uso de "drogas": controvérsias médicas e debate público. Campinas: Mercado de Letras/Fapesp, 2007. pp. 63-71.
\end{abstract}

[5] Anexo al informe estatístico anual. Junta Internacional de Fiscalización de Estupefacientes. Viena, 2001. 
repetição ou à substituição por uma substância mais potente, numa escalada que culmina com a perda do autocontrole e da capacidade de livre escolha. A dependência dessas drogas, ainda que possa variar para cada indivíduo,éuma patologia associada aos seus efeitos neuroquímicos, o que acarreta uma perda gradual de outros interesses, uma busca incessante por novas doses e uma dolorosa síndrome de abstinência - grande sofrimento psíquico e/ ou fisiológico pela suspensão do consumo. Além da dependência, elas potencializam outros transtornos mentais graves, como depressão, psicose e esquizofrenia. Crianças e adolescentes são mais vulneráveis ao consumo dessas drogas, o queé especialmente grave na incompletude de sua formação intelectual.

O consumo de drogas gera, também, graves consequências sociais, como o comportamento descontrolado e a deterioração dos laços sociais. Na medida em que seus efeitos suspendem o julgamento normal dos indivíduos, essas drogas levam a ações inconsequentes e, muitas vezes, violentas, agravadas pela incapacidade que muitos dependentes enfrentam para bancar a compra de novas doses.

Dado esse conjunto de danos e considerando que o consumo dessas drogas é totalmente prescindível, já que elas não têm aplicação médica, cabe ao Estado proibi-las. Para tanto, ele goza de legitimidade para perseguir e punir quem as produz, vende ou consome.

Segunda premissa proibicionista: a atuação ideal do Estado para combater as drogas é criminalizar sua circulação e seu consumo

Com a legitimidade conferida pela primeira premissa, o Estado deve agir em duas frentes: impedir a produção e o comércio dessas substâncias e reprimir seus consumidores. Com esse objetivo, a Convenção da ONU obriga os Estados a aplicar duras sanções penais aos produtores e vendedores dessas drogas, classificados, então, como traficantes. Para seus consumidores, as Convenções pregaram, inicialmente, a dissuasão via legislação penal. Nas últimas décadas, no entanto, a possibilidade de tratamento passou a ser considerada uma alternativa, desde que se inserisse num conjunto de sanções que deixasse clara a proibição da prática.

\section{CRÍTICA ÀS PREMISSAS PROIBICIONISTAS}

Os potenciais danos individuais e sociais do consumo de drogas não justificam a sua proibição

Todas as ações humanas engendram algum potencial de perigo ou dano. Locomoção, esporte e sexo seriam exemplos de práticas potencialmente danosas, mas, pode-se, para os fins deste artigo, limitá-las às que envolvem ingestão voluntária de substâncias (há também a 
poluição e a contaminação, que provocam danos irrefutáveis). Nesse caso, há um campo controverso, o do consumo abusivo ou desequilibrado de determinados alimentos, considerado um dos mais graves problemas de saúde pública do planeta. Limito-me, neste artigo, aos procedimentos de controle estatal no campo das drogas.

Os protocolos de pesquisa de novas drogas com aplicação médica, por exemplo, supõem riscos na forma de efeitos colaterais não previsíveis. Reconhece-se, inclusive legalmente, que eles irão ocorrer, ocasionando complicações graves e até letais. No caso das drogas de uso mais geral, o Estado se limita a regular a produção e a comercialização, não o consumo, sendo responsabilidade dos indivíduos obedecer, ou não, à prescrição médica. E há, ainda, drogas que prescindem de receituário médico, disponíveis nos balcões de farmácia para livre comercialização. Ali se encontram, por exemplo, os analgésicos, que em muitos países, como o Brasil, lideram os investimentos do mercado publicitário e estão, ao mesmo tempo, relacionados a milhares de mortes anuais, seja por reações adversas e efeitos colaterais, seja por consumo abusivo.

Mais próximos do objeto de discussão, temos as drogas psicoativas com aplicação médica, cuja comercialização segue regras mais rígidas de controle de receituário, como os ansiolíticos e os antidepressivos. Mesmo com fiscalização permanente, sabe-se que há um enorme mercado clandestino dessas substâncias, que fazem parte de muitos estoques domésticos. Com o grande crescimento do número de diagnósticos de transtornos mentais diversos, esses medicamentos ocupam, há anos, as listas dos mais vendidos, o que tem gerado grande debate entre especialistas ${ }^{6}$. Mais polêmico ainda é o avassalador crescimento do diagnóstico infantil de transtornos como o do déficit de atenção, tratados por meio do uso sistemático de estimulantes7.

Há, também, produtos que contêm substâncias psicoativas e não têm aplicação médica oficial. São as drogas mais consumidas do planeta: as bebidas alcoólicas, as bebidas estimulantes (café, chá e energéticos) e o tabaco ${ }^{8}$. Fora das listas da ONU de drogas proscritas, sofrem restrições diferentes em cada país, mas, no geral, seu comércio é legal e a decisão sobre compra e consumo é individual para os adultos. E, finalmente, as drogas psicoativas que, mesmo ilegais, são maciçamente consumidas por milhões de pessoas no mundo. Sobre sua comercialização não há controle do Estado, que se limita a pedir - e, de alguma forma, obrigar - a seus cidadãos que se mantenham distantes para que não coloquem a si è̀ sociedade em risco.

Todas essas drogas psicoativas têm grande potencial de dano, seja fisiológico, seja mental. Além disso, uma parte significativa delas é bastante tóxica, gerando grande número de mortes acidentais todos os anos. E, o que é mais importante, os indivíduos

\begin{abstract}
[6] O Rivotril (ou Clonazepam), um benzodiazepínico utilizado como calmante e inibidor de ansiedade, é o segundo medicamento mais vendido do Brasil numa lista que inclui analgésicos e anticoncepcionais.

[7] Atualmente, muitos trabalhos têm exposto e criticado esses diagnósticos e prescrições em massa. Um bom resumo de trabalhos sobre o tema pode ser lido em Angeli, Marcia. "A epidemia de doença mental". Piauí, n. 59, ago. 2011.
\end{abstract}

[8] Poderiam ser incluídos nessa lista, ainda, os solventes e outros inalantes, que são produzidos com outras finalidade comerciais, têm venda pouco controlada, mas são amplamente utilizados, sobretudo por jovens, como substâncias psicoativas (cola, éter, benzina etc.). 
podem consumi-las de maneira abusiva, seja esporádica, seja frequentemente, o que pode levar tanto a comportamentos perigosos como a quadros graves de dependência. Como se vê, tanto as drogas psicoativas livremente disponíveis como as controladas ou totalmente ilegais são perigosas. Mas, por isso, podem ser consideradas prescindíveis? Definitivamente, não.

O uso desse enorme conjunto de produtos, plantas e moléculas tem diversas motivações e parte delas são de indiscutível importância para a humanidade: ajudam no enfrentamento de doenças e infecções, aliviam a dor, apaziguam a ansiedade, melhoram o desempenho, despertam prazer, excitam, inspiram reflexões, facilitam relações sociais e, o que talvez seja uma combinação de cada uma dessas coisas, suspendem a forma ordinária de perceber o mundo. Por essas e muitas outras razões, os seres humanos as procuraram em toda a história e continuarão a fazê-lo. Como outras experiências e práticas liminares, essa alteração éarriscadae, por isso mesmo, o consumo de substâncias psicoativas foi sempre cercado de controles e interdições sociais. O exagero da premissa proibicionista é fazer do Estado, cujo motivo primordial de existência é a garantia de liberdades e direitos individuais, o promotor dessas interdições por meio da criminalização que impeça a adultos dispor de seus corpos (e ainda supor, como será discutido a seguir, que eles, com isso, deixarão de fazê-lo). Isso não é o mesmo que advogar por um cenário libertário radical, potencialmente inconsequente, em que ao indivíduo é dada uma autossuficiência abstrata. Sabe-se que o Estado se constrói em permanente arena de conflitos de interesses e valores, alguns antagônicos, mas deve haver limites para sua atuação. As práticas corporais e a ingestão de substâncias devem ser um desses marcos de autonomia, e as interdições tutelares só se justificariam em casos individuais com cuidadoso processo médico-judiciário.E, seesseéo caso do consumo de algumas substâncias hoje proscritas, então o Estado teria, por decorrência, que estender a interdição para um campo geral das drogas, dos alimentos e até de outras práticas tidas como "perigosas". O braço mais poderoso e, portanto, perigoso do Estado é a punição e, por isso, seu uso deve ser sempre considerado um recurso excepcional.

Os defensores dessa tutela lançam mão de um argumento importante. Uma vez dependentes, os indivíduos perderiam sua capacidade de livre escolha, permanecendo presos à "escravidão" da compulsão pela droga. Porém, mesmo que se reconheça que a dependência é um quadro dramático, a incapacidade de julgamento é controversa. Mais importante, essa condição não justifica a supressão do direito de escolha de outros indivíduos. Além de a interdição do uso não se sustentar pela existência do abuso, ela própria não é capaz, no caso das drogas, de impedi-lo. 
É provável que muitos dos que discordam da intromissão indevida do Estado na esfera privada continuem preocupados com o papel do Estado diante das consequências negativas que o uso de muitas dessas drogas atualmente proibidas pode acarretar. Mas é justamente a supressão da primeira premissa - a punição aos consumidores de drogas - que pode ensejar uma atuação não só mais justa, como mais eficaz. Reconhecendo que as drogas continuarão a existir, o Estado deve promover outros controles sociais e promover o autocuidado, as melhores formas possíveis de prevenção e redução de danos, ignoradas pelo proibicionismo.

Ao proibir a produção, o comércio e o consumo de drogas,

- Estado potencializa um mercado clandestino e cria novos problemas

Sustentada pela legitimidade concedida pela primeira premissa, o Estado centraliza seus esforços para impedir a circulação de drogas e dissuadir seus consumidores. Ao naturalizar a proibição como única forma de enfrentar o problema, cria-se uma falácia para sustentá-la: drogas são proibidas porque são ruins e são ruins porque são proibidas. Enquanto existirem, por essa lógica, as leis devem continuar determinando que consumi-las é errado e, portanto, punível.

No entanto, o mesmo século do proibicionismo foi o século do crescimento do consumo de drogas. Ainda que não se possa creditar o aumento do consumo de drogas ilegais à proibição, deve-se admitir que ela falhou em seus objetivos, seja de erradicá-lo, seja de contê-lo. O grande equívoco da segunda premissa é que um fenômeno de tamanha complexidade possa ser contido por um marco regulatório tão simplório, que divide drogas tão diferentes num esquema binário: permitidas e proibidas.

A produção e o comércio de drogas ilícitas são, junto com o tráfico de armas, o maior mercado criminoso do mundo. Funcionando sem nenhum tipo de regulação, o comércio dessas drogas envolve, na maior parte das vezes, exploração de trabalho, inclusive infantil, contaminação ecológica, corrupção de agentes públicos e, o queé mais grave, utilização de violência armada para demarcação de interesses e outros conflitos. É importante lembrar, nesse último ponto, que, diferente do que pregam os defensores da proibição, os dados empíricos não relacionam o consumo de drogas à violência, mesmo na dinâmica própria do comércio ilegal.Países da Europa Ocidental, por exemplo, têm, proporcionalmente, mais consumidores de drogas ilegais do que a maior parte dos países da América Latina, mas tanto o consumo como o comércio dessas substâncias se dão de forma muito menos violenta. Ou seja, a violência do comércio de drogas responde aos contextos em que ele ocorre e, portanto, ele acentua a desigualdade internacional e intranacional. 
[9] O conflito mexicano, tratado como genocídio pelas autoridades, é apontado como a causa principal de parte considerável dos $50 \mathrm{mil} \mathrm{homi-}$ cídios nos últimos quatro anos.

[10] INFOPEN, Sistema Integrado de Informações Penitenciárias do Ministério da Justiça.

[11] Comunicação oral de Pedro Abramovay, ex-secretário nacional de Justiça e professor da Fundação Getúlio Vargas, em seminário realizado no Cebrap, em novembro de 2011.

[12] Um oficial da polícia militar paulista, quando perguntado por repórter da TV Globo, em meados de 2011, se a operação contra um ponto conhecido de tráfico não seria como "enxugar gelo", posto que em alguns dias o comércio de drogas funcionaria ali novamente, sintetiza, em sua resposta, o realismo proibicionista: "Se não enxugássemos o gelo, a poça estaria muito maior".

[13] Além disso, a maior parte da população brasileira, principalmente os jovens, considera fácil obter drogas ilícitas. A última pesquisa domiciliar de abrangência nacional realizada pelo Centro Brasileiro de Informações sobre Drogas Psicotrópicas (Cebrid), em 2005 , apontou que cerca de $65 \%$ dos brasileiros acima de 12 anos consideram fácil obter maconha. $51 \%$ consideram fácil obter cocaína.
Como o tráfico é uma atividade de lucro hipertrofiado, principalmente no setor de distribuição atacadista da cadeia, parte significativa dos ganhos pode ser usada para a compra de armamentos e para corromper setores da burocracia estatal, principalmente agentes de segurança. O exemplo mais recente e dramático das consequências da guerra às drogas acontece há anos no México: extermínios quase diários no enfrentamento entre gangues e destas com o exército - cujas vítimas não se restringem aos dois lados, evidentemente?.

Como muitas outras formas de violência, as vítimas e os algozes dessa guerra são oriundos, em sua maioria, das camadas mais pobres e estigmatizadas de seus países. E a atuação das polícias se concentra normalmente em cima do mercado varejista, o mais exposto e ocupado pelos que menos lucro têm com esse comércio. Os bilhões que o tráfico movimenta, no entanto, continuam circulando pelos mercados com maneiras diversas de tornar o dinheiro legal. Ano após ano, medidas de inteligência no combate à lavagem desse capital são anunciadas, mas seu impacto no tráfico é pífio.

Prendendo cotidianamente os varejistas "de rua", rapidamente repostos num mercado tão dinâmico, a polícia faz do tráfico de drogas um dos principais responsáveis pelo alarmante crescimento do encarceramento em diversos países. No Brasil, entre os cerca de 513 mil presos, estima-se que 106 mil respondam por crimes relacionados às drogas ${ }^{10}$. E a tendência atual é que os crimes relacionados às drogas respondam por mais encarceramentos, na medida em que seu crescimento entre proporção total de detidos cresceu, entre 2006 e 2010 , $62 \%$, contra $8,5 \%$ de outros crimes ${ }^{11}$.

$\mathrm{Na}$ medida em que não cumpriam a meta de um "mundo livre de drogas" para os próximos decênios, as diversas Convenções Internacionais postergavam seus objetivos. No último deles, o encontro da Comission on Narcotic Drugs (CND) em Viena, 2009, a nova justificativa tomou contornos oficiais: se um mundo sem drogas parece pouco factível num futuro próximo, continuar a guerra é o que garante que o consumo não atinja níveis catastróficos. Na verdade, a Convenção apenas se apropria de uma perspectiva que já era clara para a maior parte dos agentes envolvidos no cotidiano da guerra às drogas, que nunca vislumbraram uma vitória definitiva. É uma guerra na qual se costuma comemorar "vitórias" parciais, como a prisão de traficantes e a apreensão de drogas, que seriam capazes de retirar das ruas o "veneno" que o inimigo, cada vez mais perigoso, distribui ${ }^{12}$. Ignorando que há substituição permanente de função e que apenas uma pequena parte do que circula no mercado é apreendida, a polícia exalta mais os procedimentos do que os resultados práticos: os preços da cocaína e de sua versão tragável, o crack, têm permanecido praticamente estáveis em São Paulo há quase duas décadas ${ }^{13}$. 
Por fim, sob o proibicionismo, os consumidores de drogas são conduzidos a um contato estreito com o crime. Envoltas por uma aura marginal que tanto seduz como estigmatiza, as drogas tornam-se um marcador de coragem e virilidade. Demonizadas por campanhas que carregam mais pânico do que informação, duas drogas tão diferentes como maconha e cocaína, por exemplo, misturam-se não só no imaginário, mas nos locais e/ ou nas pessoas que as vendem. Diferentemente do que ocorre com as drogas legais, sobre as quais os serviços de saúde podem fornecer informações a respeito de usos mais seguros e, assim, estimular o autocuidado, o consumidor de drogas ilícitas é confrontado com uma única decisão: interromper o consumo ou manter-se escravo da droga.

\section{Ofortalecimento das críticas e a modernização do paradigma:}

"Guerra contra o tráfico, tratamento para o viciado"

Nos últimos anos, as críticas ao paradigma proibicionista não apenas se fortaleceram como conseguiram escapar do lugar a que foram estrategicamente relegadas ao longo do século XX: um exotismo inconsequente ou fruto do comprometimento pessoal de defender o uso de drogas como positivo ${ }^{14}$. Abordagens pragmáticas e realistas, como a redução de danos, conseguiram se distanciar das premissas proibicionistas e alcançar bons resultados, com os quais ganharam, lentamente, credibilidade. Guiadas pelo pressuposto de que cabe aos profissionais de saúde a minimização dos danos e não a erradicação das drogas, as políticas de redução de danos foram decisivas para recolocar os termos do debate ${ }^{15}$, principalmente no cuidado com o consumidor.

Dessa forma, o encarceramento de usuários/ dependentes foi sendo mais e mais considerado uma ação estatal anacrônica e desumana. Em vez de puni-los com prisão, o Estado deveria tratá-los, mesmo que contra sua vontade. Essa perspectiva, já prevista pelas Convenções, se configura hoje como uma espécie de "modernização" da premissa proibicionista e influenciou, no Brasil, importantes mudanças na atualização da legislação sobre o tema. A Lei de Drogas (n. 11.343), promulgada em 2006 , endureceu o combate ao tráfico e manteve a criminalização do consumidor - o fato de o uso estar incluído no código penal é prova disso - , mas eliminou a pena de prisão para os indivíduos flagrados com drogas para seu próprio uso, estipulando penalidades que vão de advertência verbal à prestação de serviços públicos. Na outra ponta, a lei aumentou a pena mínima de prisão para quem portar drogas destinadas ao tráfico de três para cinco anos ${ }^{16}$.

Chamo a atenção para duas consequências práticas da lei: ao não estipular quantidades ou outros critérios objetivos para definir se a droga é destinada paravenda ou para o consumo, continua sendo conferida à au-

\begin{abstract}
[14] Os crescentes movimentos populares pela mudança da lei de drogas, dos quais se destaca a Marcha da Maconha, têm tido dois papéis fundamentais: desmistificar, por meio da ocupação do espaço público, o caráter marginal associado às drogas e, ao mesmo tempo, reivindicar sua existência política para além da apologia do consumo de drogas, argumento normalmente utilizado para retirar sua legitimidade.
\end{abstract}

[15] O conceito de redução de danos é muito controverso, sendo objeto de disputa semântica entre especialistas. Para uma discussão mais aprofundada, ver Fiore, Maurício, op. cit.

[16] Considerado crime hediondo, a pena para o tráfico de droga é comparável às previstas para homicídio $e$ estupro. 
[17] "Para determinar se a droga destinava-se a consumo pessoal, o juiz atenderá à natureza e à quantidade da substância apreendida, ao local e às condições em que se desenvolveu a ação, às circunstâncias sociais $e$ pessoais, bem como à conduta e aos antecedentes do agente", Lein.11.343. art. 28, parágrafo terceiro.

[18] Ver Boiteux, Luciana et al. "Relatório de pesquisa tráfico e constituição". Pensando o direito. Brasília/ Rio de Janeiro: Ministério da Justiça, 2009; e Prisão provisória e lei de drogas: um estudo sobre os flagrantes de tráfico de drogas na cidade de São Paulo. São Paulo: Núcleo de Estudos da Violência, 2011.

[19] Entre outros, três ex-presidentes, Fernando Henrique Cardoso, Cesar Gaviria (Colômbia) e Ernesto Zedillo (México), o ex-secretário geral da ONU, Kofi Annan, e o ex-secretário de Estado dos EUA, George Shultz.

[20] Profissionais da saúde ligados à redução de danos, pesquisadores e líderes de movimentos antiproibicionistas são alvo frequente de ataques que os estereotipam como "simpatizantes ou defensores das drogas".

[21] Husak, Douglas e Marneffe, Peter de. The Legalization of Drugs: for and against. Nova York: Cambridge: 2005. pp. 26-27. toridade policial a responsabilidade dessa interpretação e a instauração de inquérito, avaliado posteriormente pelo Ministério Público e pelo poder Judiciário ${ }^{17}$. Duas pesquisas recentes mostraram que a lei encarcera jovens, normalmente pobres, primários eque portam pouca quantidade de drogas. Além disso, uma vez enquadrados como traficantes, grande parte deles responde ao processo encarcerados e dificilmente conseguem escapar de condenaçã̃o ${ }^{18}$. Em segundo lugar, ao aumentar o fosso que divide consumidores e traficantes, a lei parece ter aumentado o rigor policial, que desde sua promulgação cresceu substancialmente, como citado há pouco. A mudança da lei, inegavelmente importante ao suprimir a pena de prisão de usuários, parece encerrar um dilema:por quais caminhos conduzir as críticas ao proibicionismo.

Sua concretização está implícita, por exemplo, na mais influente confrontação política internacional, a Comissão Global de Política de Drogas, que reúne líderes políticos importantes ${ }^{19}$, artistas e especialistas célebres. $O$ argumento principal do grupo é que a guerra às drogas é um fracasso, com terríveis efeitos colaterais do mercado ilegal de drogas e das violentas e dispendiosas tentativas de combatê-lo. Seu principal ataque, assim, se dá à segunda premissa proibicionista, a de que as drogas devem ser combatidas penal e militarmente.

Como essa, outras críticas ao proibicionismo não estão direcionadas a sua premissa fundamental, a de que o Estado pode e deve interferir na decisão individual de consumir drogas. Há, sem dúvida, um componente tático nessa opção. O debate sobre drogas está pautado há mais de um século pelo pânico moral e por um formato belicista no qual questionamentos da primeira premissa - o Estado deve, realmente, proibir o consumo de drogas? - são normalmente interpretados como simpatia interessada ou inconsequente pelo inimigo ${ }^{20}$. Quando questiona o resultado da guerra, a crítica se torna mais palatável e pode angariar mais apoio.

Caberia uma reflexão sobre os seus limites. A manutenção da premissa de que as drogas são ruins a ponto de justificar sua proibição é o esteio mais profundo do paradigma. Assemelhando-se a muitos outros debates políticos contemporâneos, a discussão sobre política de drogas ensejará, necessariamente, conflitos entre valores morais que, no mais das vezes, terminam em um estéril polemismo. É possível, no entanto, que mudanças significativas possam ocorrer sem que os limites ao papel do Estado sejam questionados?

Seguindo a provocação de David Husak ${ }^{21}$, uma das maneiras retóricas de recolocar o papel do Estado na discussão é inverter a pergunta que normalmente é feita aos críticos do proibicionismo. Assim, em vez de responder passivamente à questão "Por que o Estado deve descriminalizar o uso de drogas?", deve-se colocar outra: "Por que o Estado deve proibir o uso de drogas?". A estratégia de questionar a 
primeira premissa, ainda que politicamente mais delicada, pode abalar de maneira mais consistente todo o paradigma. A ruína histórica de outro modelo proibicionistaé didática. Na década de 1920, os EUA, depois de décadas de pressão de grupos religiosos, comunitários e feministas, conseguiu reunir apoio político suficiente para uma ambiciosa empreitada: extirpar o consumo de álcool do país². A "Lei Seca" vigorou durante treze anos e, até hoje, é o exemplo mais evocado de fracasso por conta de suas consequências: aumento de crimes violentos, consolidação do crime organizado e envenenamentos por conta da produção clandestina. Hoje, ela não é considerada um delírio proibicionista apenas por ter fracassado, mas porque seu fundamento autoritário - o Estado pode, em defesa da sociedade, proibir que indivíduos comprem álcool legalmente - não parece nem um pouco plausível, o que torna pouco provável sua reintrodução.

\section{ALGUNS PRESSUPOSTOS PARA MODELOS ALTERNATIVOS}

Como dito acima, defender um modelo alternativo ao proibicionismo não é afastar o Estado do problema, mas rediscutir o seu papel para que ele atue com mais eficiência dentro de limites democráticos. A luta pela mudança do paradigma deve, portanto, ser simultânea à construção de legislações e políticas públicas queestabeleçam normas justas, promovam práticas menos nocivas e atendam da melhor forma possível os problemas que o consumo de drogas inexoravelmente causará. Apresento, de forma bastante resumida, algumas sugestões gerais oriundas da literatura e de algumas experiências internacionais:

\section{Valorizar o autocuidado es controles sociais}

A alteração sistemática da consciência por meio de substâncias não é uma ação isolada. Os indivíduos o fazem em contextos sociais específicos que estão, como todos os outros, repletos de valores, regras e sentidos que tanto incitam quanto estabelecem parâmetros. Aos efeitos desordenadores das drogas, sempre são postos controles e freios sociais, inclusive com aplicação de sanções. Num exemplo atual, indivíduos e sociedade se equilibram entre estímulos, valores e sanções que dizem respeito ao consumo de álcool. O Estado, nesse caso, se ausenta da tarefa de regular o mercado e desestimular o uso, mas, ainda assim, a maior parte dos bebedores não pode ser considerada socialmente disfuncional ou dependente crônica. Quando se reconhece que é impossível suplantar os problemas que o consumo de drogas inevitavelmente pode causar, percebe-se com mais facilidade que nenhuma medida preventiva será mais eficiente do que o autocuidado e o fortalecimento de laços sociais.
[22] Uma obra recente fundamental para se aprofundar na instituição da "Lei Seca" é Okrent, Daniel.Last Call: the rise and tall of Prohibition. Nova York: Scribner, 2010. 
[23] Ver Greenwald, Gleen. Drug Descriminalization in Portugal: lessons for creating fair and successful drug policies. Nova York: Cato Institute, 2009
Há que se evitar, também, a crença de uma regulamentação onipresente da produção e do comércio de substâncias psicoativas. Medidas de controle e desestímulo são fundamentais - aumento de preços, restrição de pontos de venda, limitação de quantidade ofertada, controle de dosagem etc. - , mas devem ser levados em conta os padrões de consumo mais comuns para que não se configurem num grande incentivo à hipertrofia do inevitável mercado clandestino.

\section{Descriminalização (de fato) do consumo e estipulação com critérios objetivos}

Uma política justa e eficiente sobre drogas pressupõe, no mínimo, a descriminalização do consumidor. Uma experiência prática que tem sido apontada como modeloéa portuguesa. Háuma década, uma novalei manteve a ilegalidade das drogas, mas tornou seu porte para consumo uma infração administrativa. Caso flagrado com drogas, o indivíduo é ouvido por uma junta civil composta de psicólogos, médicos e assistentes sociais que, de forma compartilhada e sob a perspectiva do cuidado à saúde integral, decidem se é o caso de um tratamento ou de sanções mais sérias, como multas. Em boa parte dos casos envolvendo adultos e drogas como maconha, o papel do Estado se encerra, temporariamente, nesse contato. As normas portuguesas estabelecem com mais clareza qual a quantidade que tipifica a posse para uso (estimada para dez dias de consumo), e os resultados obtidos desde a mudança são positivos, como a queda do número de consumidores problemáticos e a diminuição do envolvimento de crianças com drogas ${ }^{23}$. A maior conquista do modelo, no entanto, é demonstrar que a supressão da punição não faz com que todos, principalmente os jovens, corram para o traficante mais próximo em busca de drogas. Sua introdução, no entanto, deve ser adaptada a contextos como o brasileiro, caracterizado por grande seletividade penal contra populações vulneráveis. Tirar o consumidor da órbita do direito penal por meio de critérios claros para definiro queé porte para consumo e para tráficoéuma mudança menos polêmica e com impactos positivos.

\section{Planejamento de ações de acordo com as especificidades de cada droga}

O uso recorrente do termo "drogas" neste artigo pode levar à conclusão equivocada de que se está sugerindo que elas devem ter, por parte do Estado, tratamento equivalente. Sob o proibicionismo, um único critério obscuro - legalidade versus ilegalidade - uniformiza substâncias muito diferentes. Políticas eficientes devem se basear em dados empíricos sobre os efeitos, os riscos potenciais e os padrões de consumo de cada uma delas. É com base nessa especificidade que grande parte dos críticos do proibicionismo defendem a possibilidade de mudança imediata, por exemplo, do estatuto jurídico da maconha, a droga ilegal mais consumida do planeta. 
Não obstante seu consumo possa acarretar danos e nem todos eles serem plenamente conhecidos, a maconha não apresenta toxicidade letal e o padrão de consumo mais comum não é problemático. Além disso, a manutenção da maconha na lista de plantas proscritas tem dificultado a investigação sobre a sua ampla e bem demonstrada função medicinal24.

Outras drogas ilegais e bastante difundidas, como a cocaína, demandariam modelos mais complexos de regulamentação, algo próximo do que atualmenteéfeito para os medicamentos controlados. Nesses casos, o desafio seria equilibrar uma política que garantisse mais controle sem criminalização, desestimulando o mercado clandestino 25 . Não se deve esquecer que cada vez mais substâncias estarão disponíveis, demandando novas formas de o Estado lidar com a questão. Hoje, proibir tem sido a resposta. Desafiados por novas substâncias ou formas de alterar a consciência no futuro, os Estados poderão pagar um preço alto por não ter testado e aprimorado outras alternativas.

O álcool e o tabaco são outros bons parâmetros para o planejamento da inclusão das drogas ilegais na supervisão estatal. O álcool, legalizado, sofre o mesmo controle de qualidade dos alimentos e seu comércio, desde que tributado,élivre(preçose pontos devenda), sendo apenas fiscalizado, com pouco rigor, o acesso por menores de idade. Sua publicidade, objeto de investimentos maciços, praticamente não sofre restrições ${ }^{26}$. Portanto, é um exemplo de omissão do Estado, o que se explica em grande parte pela pressão dos interessados diretos no seu comércio. Já o tabaco, também legalizado, por outro lado, vem sendo objeto de recente intervenção estatal sob quatro vertentes principais, justificada pelos incontestáveis danos epidêmicos gerados pelo seu consumo: disseminação de informações ealertas sobreseus danos potenciais, veto quase total da publicidade, aprimoramento do atendimento aos dependentes e restrição de locais de uso (nesse caso, com a justificativa de proteger outros indivíduos). Independente das controvérsias sobre seus exageros, trata-se de um exemplo duplamente bem-sucedido: sem adotar as premissas proibicionistas, o Brasil viu diminuir, em vinte anos, a proporção de fumantes em cerca de 50\%. Outros países também têm alcançado, com políticas equivalentes, bons resultados ${ }^{27}$. A regulação dos mercados de álcool e tabaco, drogas legais, demonstram, portanto, que a ausência de políticas públicas não diz respeito à legalidade de uma droga. Mercados legais podem ser bem (tabaco) ou mal (álcool) regulados fora do paradigma proibicionista.

\section{PERSPECTIVAS DE MUdANÇAS NO BRASIL}

Não obstante o inegável crescimento das vozes dissonantes e dos movimentos políticos de contestação ao paradigma proibicionista, que certamente tem e terá papel decisivo na mudança do modelo, o horizonte de mudanças práticas não parece promissor no Brasil.
[24] VerMalchier-Lopes, Renato eRibeiro, Sidarta.Maconha, cérebro e saúde. Rio de Janeiro: Vieira e Lent, 2007.

[25] Para que cenários futuros de regulação sejam viáveis, é importante que não se descartem algumas estruturas de controle já estabelecidas internacionalmente, inclusive pela própria Convenção. Para uma discussão detalhada e minuciosa de cenários de regulação, uma obra fundamental é After the War on Drugs: Bluprint for Regulation. Londres: Transform Drug Policy Foundation, 2009.

[26] Somente as bebidas com mais de treze graus na escala Gay-Lussac sofrem algum tipo de restrição publicitária no Brasil. Assim, a maior parte dos fermentados, como as cervejas e os vinhos, além dos ices (misturas de refrigerantes e bebidas destiladas), não é considerada, para fins publicitários, bebida alcoólica.

\footnotetext{
[27] Nos EuA, um em cada dois homens fumava na década de 1960 . Hoje, esse número é inferior a dois em cada dez, com viés de queda. Ver Chartbook on trends in the health of americans. EUA: National Center for Health Statistics, 2007.
} 
[28] Esses projetos ignoram que legislação semelhante, aprovada nos EUA na década de 1980, é duramente criticada por ter aumentado o processo de encarceramento em massa, de nítida seleção social/ racial, que faz dos EUA o maior encarcerador do mundo. Sobre esse ponto, ver especialmente Vagins, Debora J. e McCurdyJesselyn.Cracks in the system: twenty years of the unjust federal crack cocaine law. Washington: America Civil Liberties Union, 2006.

[29] Depois de declarar à imprensa que o governo vinha estudando mecanismos para diminuir o encarceramento em massa de pequenos traficantes, sugerido por documentos do próprio Ministério da Justiça, o ex-secretário nacional de Justiça, Pedro Abramovay, foi "desnomeado" da Secretaria Nacional de Política sobre Drogas antes de assumir o cargo.

[30] As comunidades terapêuticas são muitas vezes ligadas a grupos religiosos e exigem a abstinência total durante o isolamento, o que é criticado por especialistas. Além disso, um relatório recente do Conselho Federal de Psicologia apontou problemas graves em muitas comunidades, inclusive tortura. Ver " 4 Relatório Nacional de Inspeção de Direitos Humanos: locais de internação para usuários de drogas". Brasília: Conselho Federal de Psicologia, 2011.

[31] Burgierman, Denis Russo. $O$ fim da guerra: a maconha e a criação de um novo sistema para lidar com as drogas. São Paulo: Leya, 2011. pp. 54-6o.

[32] Ao apontar a repercussãogeral, o STF indica que ela deve ser usada como parâmetro norteador de decisões semelhantes em instâncias inferiores.

Recebido para publicação em 8 de dezembro de 2011.

\section{NOVOS ESTUDOS}

\section{CEBRAP}

92, março 2012

pp. 9-21
Julgando pelo histórico de atuação do legislativo sobre o tema, é improvável que alguma mudança além do aprofundamento do modelo atual possa ocorrer. Desde a promulgação da Lei de Drogas, em 2006, os projetos que ganharam algum destaque e maior apoio no Congresso previam, por exemplo, o retorno da pena restritiva de liberdade para consumidores, dessa vez sob a forma de tratamento compulsório e com a justificativa de que a lei atual havia eliminado as ferramentas da dissuasão do Estado. Outra iniciativa, dada a grande repercussão do aumento do consumo de crack pelo país, tentou endurecer ainda mais as penas para os traficantes dessa forma específica de cocaína ${ }^{28}$.

Mudanças significativas dificilmente virão, também, do atual Executivo federal. Ainda que haja vozes dissonantes no interior do governo, discursos que apresentem qualquer crítica da proibição são evitados ${ }^{29}$, e a pauta de atuação tem se concentrado nos investimentos ao combate ao tráfico, controle de fronteiras e tratamento de dependentes. Nesse último aspecto, que mereceria uma discussão específ$\mathrm{ca}$, medidas anunciadas recentemente aumentaram os investimentos no atendimento público aos dependentes, mas, ao mesmo tempo, garantiram o financiamento das comunidades terapêuticas, instituições privadas em que, normalmente, se privilegia a internação como forma de tratamento, decisão bastante controversa ${ }^{30}$.

Num livro recente sobre alternativas ao proibicionismo ${ }^{31}$, o jornalista Denis Burgierman usou uma metáfora interessante para explicar a inércia dos políticos com relação ao tema: eles seriam dependentes das drogas; não da ingestão dessas substâncias, mas do seu uso eleitoral. De fato, os políticos esperam não só ganhar votos quando defendem o combate sem trégua às drogas, como conseguem tirá-los de adversários que ousem propor o debate sobre qualquer alternativa. Mas, se o fazem, é também porque encontram forte ressonância e apoio em praticamente todos os segmentos sociais. No caso das drogas, prevalece uma regra política: quanto maior a ambição eleitoral, menos se deve mexer no vespeiro. Apenas prometa odiar elutar contra as vespas.

O alento pode vir da instância máxima do Judiciário, que não depende diretamente de votos. Este ano, o Supremo Tribunal Federal deve julgar, com repercussão geral ${ }^{32}$, a inconstitucionalidade da atual lei de drogas, que criminaliza a posse de drogas para consumo próprio. Se seguirem a decisão de seus colegas da Colômbia e da Argentina e considerarem inconstitucional a punição aos cidadãos que portem droga para consumo, os ministros brasileiros serão os responsáveis pelo único, mas extremamente relevante, questionamento ao paradigma proibicionista que se pode vislumbrar a curto prazo no Brasil.

MAURíCIO FIORE é doutorando em Ciências Sociais pela Unicamp e pesquisador do Cebrap e do Neip (Núcleo de Estudos Interdisciplinares sobre Psicoativos). 